UCRL- JC- 125769

PREPRINT

\title{
Emission of Secondary Particles from Metals and Insulators at Impact of Slow Highly Charged Ions
}

T. Schenkel

A. V. Barnes

M. A. Briere

A. Hamza

A. Schach von Wittenau

D. H. Schneider

Prepared for Submittal to

11 th International Workshop on Inelastic Ion Surface Collisions

Sept. 22-27, 1996, Wangerooge, Germany

October 31,1996

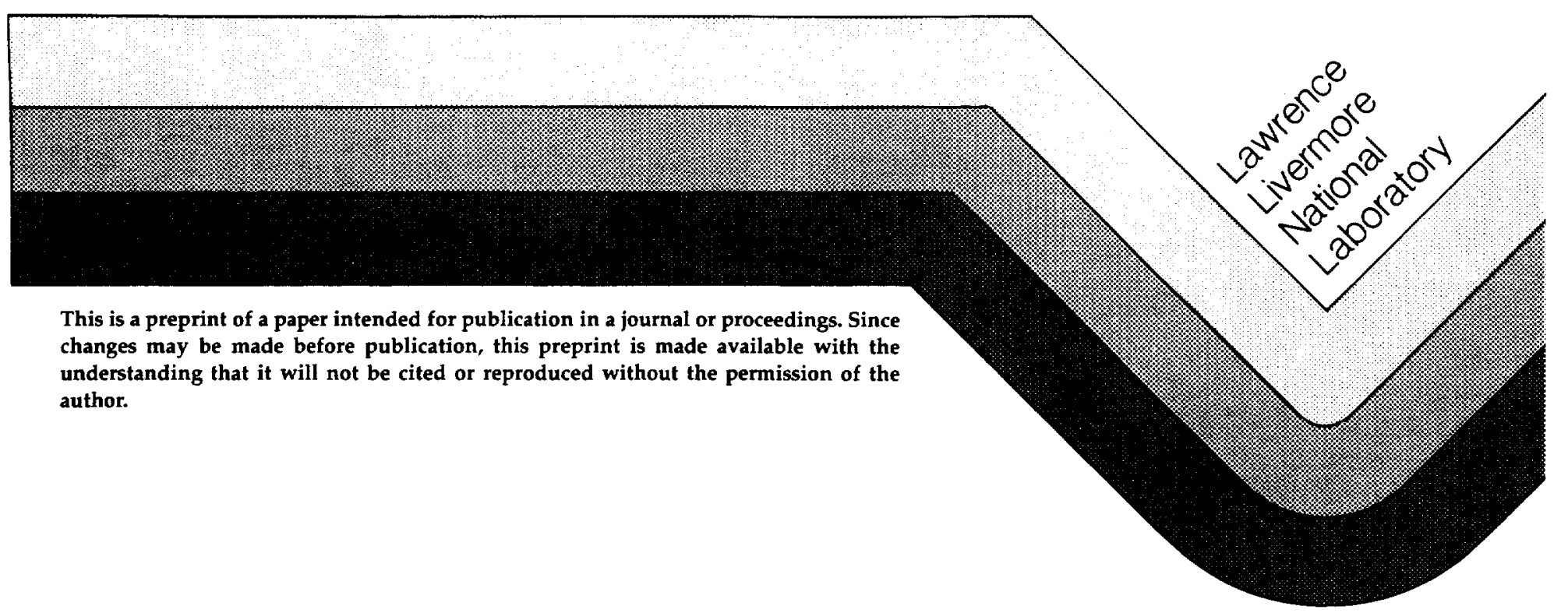




\section{DISCLAIMER}

This document was prepared as an account of work sponsored by an agency of the United States Government. Neither the United States Government nor the University of California nor any of their employees, makes any warranty, express or implied, or assumes any legal liability or responsibility for the accuracy, completeness, or usefulness of any information, apparatus, product, or process

disclosed, or represents that its use would not infringe privately owned rights. Reference herein to any specific commercial product, process, or service by trade name, trademark, manufacturer, or otherwise, does not necessarily constitute or imply its endorsement, recommendation, or favoring by the United States Government or the University of California. The views and opinions of authors expressed herein do not necessarily state or reflect those of the United States Government or the University of California, and shall not be used for advertising or product endorsement purposes. 


\title{
Emission of Secondary Particles from Metals and Insulators at Impact \\ of Slow Highly Charged Ions
}

\author{
T. Schenkel, ${ }^{1,2}$ A. V. Barnes ${ }^{3}$, M. A. Briere ${ }^{1,4}$, A. Hamza ${ }^{1}$, A. Schach von Wittenau, \\ and D. H. Schneider ${ }^{1}$
}

${ }^{1}$ Physics and Space Technology Directorate, Lawrence Livermore National Laboratory, Livermore, CA 94550, USA

${ }^{2}$ Institut für Kernphysik der J. W. Goethe University, D-60486 Frankfurt, Germany

${ }^{3}$ Department of Physics, Vanderbilt University, Nashville, TN

4present address: Physics Department, University of Rhode Island, S. Kingston, RI

The emission of secondary electrons and ions from clean $\mathrm{Au}, \mathrm{C}_{\mathrm{x}} \mathrm{H}_{\mathrm{y}}-\mathrm{Au}$ and $\mathrm{SiO}_{2}$ surfaces at impact of slow $\left(v \approx 0.3 \mathrm{v}_{\text {Bohr }}\right)$ ions has been measured as a function of incident ion charge for $1+\leq q \leq 75+$. Electron yields from thermal silicon dioxide films $(150 \mathrm{~nm}$ on Si) are found to be lower than those from $\mathrm{Au}$ and $\mathrm{C}_{\mathrm{x}} \mathrm{H}_{\mathrm{y}}-\mathrm{Au}$ for $\mathrm{q}>3+$. Yields of negative secondary ions from $\mathrm{SiO}_{2}$ and $\mathrm{C}_{\mathbf{x}} \mathrm{H}_{\mathrm{y}}$-Au were recorded in parallel with electron emission data and exhibit a $\mathrm{q}^{\mathrm{n}}, \mathrm{n} \approx 4$, dependency on incident ion charge. A direct comparison of collisional and electronic contributions to secondary ion production from $\mathrm{SiO}_{2}$ films using a beam of charge state equilibrated $\mathrm{Xe}^{\mathrm{q}-99 \mathrm{q}}$ (at $2.75 \mathrm{keV} / \mathrm{u}$ ) shows positive and negative secondary ion yield increases with incident ion charge of $>400$. Results are discussed in relation to key signatures of electronic sputtering by Coulomb explosions. 


\section{Introduction}

Ions traveling in solids develop an equilibrium charge state distribution. Initial charge states of highly charged ions used in this study are much larger than the mean equilibrium charge states that correspond to their low velocities $\left(v \approx 0.3 v_{\text {Bohr }}, E_{k i n} \leq 3\right.$ keV/u) [1]. "Slow" highly charged ions are differentiated from "fast" ions of similar high charge states with velocities $v \gg v_{B o h r}$, which are produced by charge state equilibration in gaseous or solid targets at $\mathrm{MeV} / \mathrm{u}$ energies.

Studies of the interaction of slow highly charged ions (HCI) with surfaces have drawn considerable attention over the last decade [2-4]. Having reached a critical distance from a metal surface, incoming ions begin to resonantly capture electrons from the target conduction band into highly excited Rydberg states, with binding energies approximately equal to the metal workfunction. Corresponding principal quantum numbers of $n \approx 60$ can be estimated from the "classical-over-the-barrier-model" [3] for the interaction of $\mathrm{Au}^{69+}$ with Au surfaces. While ions approach a surface, excited states decay by autoionization and resonant ionization processes, the former giving rise to electron emission into the vacuum $[5,6]$. Typical transition times for Auger- and radiative transitions are far too long for the ion to de-excite completely above the surface. With most electrons populating high n Rydberg states, a highly excited, but neutral "hollow atom" finally hits the surface. It has been suggested that hollow atom formation in front of insulator surfaces is relatively inhibited in comparison to impact on metals [7]. At impact, electrons in Rydberg states with radii in excess of a characteristic surface screening length are -peeled off, and a fraction of electrons escapes into the vacuum. De-excitation continues 
below the surface via rapid side-feeding processes of target electrons into energetically favorable ion vacancies, accompanied by a multitude of radiative and Auger transitions. Total neutralization times are in the order of tens of femtoseconds. During this time highly charged ion potential energies of up to several hundreds of $\mathrm{keV}$-are dissipated. The quantitative differentiation of the various energy dissipation channels (target lattice excitations, secondary electrons, photons, $x$-rays, Auger-electrons, secondary ions and neutrals) is the underlying challenge of this rapidly developing field [2-4]. In a model of electronic sputtering, Parilis et al. have proposed a Coulomb explosion mechanism for the description of high secondary particle yields from insulators and poor conductors at highly charged ion impact [8]. The model assumes that electron emission leads to the formation of a charge depleted region on insulator surfaces. Coulomb repulsion between ionized target atoms results in an explosive lattice relaxation before charge neutrality can be reestablished. The question of the occurrence of Coulomb explosions in the interaction of $\mathrm{HCI}(\mathrm{q}<16+)$ with insulators and semi conductors had been controversial for many years [8-10]. Evidence for electronic sputtering and damage production by Coulomb explosions was found in studies of secondary ion emission from thin $\mathrm{SiO}_{2}$ films and defect formation on mica using slow very highly charged ions with $q>35+[2,11]$.

\section{Experimental arrangement}

Beams of multiply and highly charged ions were extracted from the electron beam ion trap (EBIT) at Lawrence Livermore National Laboratory [2]. The experimental setup has previously been described in detail $[2,12]$. Relative electron yields were measured using pulse height analysis of micro channel plate signals. Previously determined absolute 
electron yields from Au targets were used for calibration [6]. For electron emission and time-of-flight secondary ion mass spectroscopy (TOF-SIMS) measurements, a highly charged ion flux of $<1000$ ions/s was used, and each TOF-SIMS-cycle was triggered by secondary particles emitted from the target at impact of an individual HCI under normal incidence. High yields of secondary electrons and protons were used in TOF-SIMS of negative and positive secondary ions. Start efficiencies were $100 \%$ for electron- and 10 $80 \%$ for proton starts. Triggering off secondary photons was omitted due to low start efficiencies. Start signals, secondary ion stop signals and secondary electron pulse heights were all detected by a single, annular micro channelplate detector. TOF-SIMS spectra where recorded with a multi-stop multichannel scaler. For preparation of a $2.75 \mathrm{keV} / \mathrm{u}$ Xe-ion beam in charge state equilibrium, a $10 \mathrm{~nm}$ thick carbon foil was placed into the beam line in front of the annular micro channelplate detector. Negative secondary ion spectra and electron emission pulse height distributions were recorded in parallel. Targets consisted of silicon dioxide films (150 and $50 \mathrm{~nm}$ on $\mathrm{Si}$ ) and Au crystals. For measurements of highly charged ion induced desorption of surface adsorbates and adsorbate effects on electron emission, a film of hydrocarbons was deposited on a $\mathrm{Au}$ crystal before insertion into vacuum. Targets could be cleaned in situ by low energy Ar sputtering.

\section{Results and discussion}

\subsection{Secondary electron emission}

Pulse height distributions resulting from bursts of secondary electrons emitted from $\mathrm{C}_{\mathrm{x}} \mathrm{H}_{\mathrm{y}}-\mathrm{Au}$ and $\mathrm{SiO}_{2}(150 \mathrm{~nm}$ on $\mathrm{Si})$ targets at impact of $\mathrm{Th}^{75+}$ at $\mathrm{v}=7.49 \times 10^{5} \mathrm{~m} / \mathrm{s}$ are shown 
in Fig. 1. Targets were biased at $-2 \mathrm{kV}$ to allow for efficient secondary electron collection. Secondary electron yields $(\gamma)$ from the $\mathrm{SiO}_{2}$ film are a factor of two lower than yields from $\mathrm{C}_{x} \mathrm{H}_{y}-\mathrm{Au}$. Fig. 2 shows the charge dependency of secondary electron emission yields for

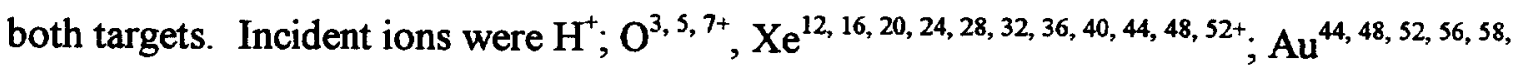
${ }^{64,69+}$ and $\mathrm{Th}^{44,48,52,54,58,59,62,66,69,70,75+}$; with corresponding potential energies 0.01 $\mathrm{keV}<\mathrm{E}_{\mathrm{pot}}<198 \mathrm{keV}$. Kinetic energies were $9 \mathrm{keV} \times \mathrm{q}$. Using a clean Au target, relative electron emission yields were calibrated with previously measured total electron emission yields [6]. Electron yields from the Au target increased by $\sim 10 \%$ after removal of the hydrocarbon layer. Electron yields from both targets increase nearly linearly with incident ion charge up to the highest charge states, with yields from $\mathrm{SiO}_{2}$ being lower than from Au targets except for incident charged states $\mathrm{q}<5+$. At the $\mathrm{q}=52+$ triplet of $\mathrm{Xe}^{52+}$ (total ion potential energy, $\left.\mathrm{W}_{\mathrm{pot}}=121 \mathrm{keV}\right), \mathrm{Au}^{52+}(57.6 \mathrm{keV})$, and $\mathrm{Th}^{52+}(54.8 \mathrm{keV})$, previously observed [6] differences in emission yields reflect less efficient conversion of $\mathrm{HCI}$ inner shell potential energy into electronic excitations leading to electron emission. It is remarkable to note that the scaling of $\gamma$ with $\mathrm{W}_{\text {pot }}$ for incident $\mathrm{Au}^{52+}$ and $\mathrm{Xe}^{52+}$ is the same for both the metallic and the insulating target, with $\gamma$ increasing by $\sim 1.28$ while $\mathrm{W}_{\text {pot }}$ increases by a factor of 2.2. In the reverse situation of constant $\mathrm{HCI}$ potential energy, $\mathrm{W}_{\text {pot }} \approx 121 \mathrm{keV}$, for impact of $\mathrm{Xe}^{52+}$ and $\mathrm{Th}^{66+}$-ions, $\gamma$ scales, for both targets (Au: 1.35, $\mathrm{SiO}_{2}: 1.21$ ), approximately like the ratio of incident $\mathrm{HCI}$ charges (i. e. 1.27).

The dependencies of secondary electron emission from $\mathrm{C}_{\mathrm{x}} \mathrm{H}_{\mathrm{y}}-\mathrm{Au}$ and $\mathrm{SiO}_{2}$ targets on incident ion velocity is shown in Fig. 3 for impact of $\mathrm{Xe}^{44+}$-ions. The incident ion velocity dependency of positive secondary ion emission from $\mathrm{SiO}_{2}$ films is also included. In agreement with previous measurements [4-6], secondary particle emission yields are 
found to change only very weakly with incident ion velocity in the velocity regime used in this study $\left(0.2 \mathrm{v}_{\mathrm{Bohr}}<\mathrm{v}<0.5 \mathrm{v}_{\mathrm{Bohr}}\right)$. In the framework of the classical over the barrier model [3], the distance of first resonant electron capture by incident ions from a metal target conduction band, and therefore the time for above surface neutralization and electron emission, are inversely proportional to the target workfunction. In the case of $\mathrm{SiO}_{2}$, an effective workfunction can be defined as the sum of band gap energy and surface electron affinity $(\sim 11 \mathrm{eV}$ as compared to $\sim 5 \mathrm{eV}$ for $\mathrm{Au})$. The insensitivity on incident ion velocity confirms that above surface autoionization is not the dominant contribution to secondary electron emission from both targets.

Electron emission yields from insulators at impact of singly charged ions are known to be higher than from conductors and semiconductors $[13,14]$. This has been attributed to lower surface barriers and larger inelastic mean free paths for excited electrons in insulators. We reproduce this result, measuring slightly higher yields from $\mathrm{SiO}_{2}$ than from $\mathrm{Au}$ for incident protons and $\mathrm{O}^{3+}$ ions. It has been suggested that hollow atom formation is strongly inhibited for impact of highly charged ions like $\mathrm{N}^{6+}$ and $\mathrm{Ne}^{9+}$ [7] on insulators like LiF. Winter et al. [4] found that less efficient above surface electron emission was more than compensated by more efficient below surface emission from LiF, resulting in higher electron yields from LiF than from Au targets for impact of slow $\mathrm{HCI}$ with $\mathrm{q}<10+$. Our results show that this is not the case for highly charged ion impact on $\mathrm{SiO}_{2}$ films.

Investigating the influence of characteristic materials parameters such as the surface screening length, effective workfunction, charge carrier mobility and electronphonon coupling constant, to name a few, is necessary to gain a more complete 
understanding of $\mathrm{HCI}$ de-excitation processes above (e. g. resonant neutralization and ionization, autoionization), at (screening, peeling-off) and below (e. g. side-feeding, Auger neutralization) surfaces and their contributions to $\mathrm{HCI}$ induced electron emission.

\subsection{Secondary ion emission}

In order to be able to directly compare contributions to secondary ion yields from collisional and electronic, i. e. ion charge state dependent, processes, we used a $10 \mathrm{~nm}$ thick carbon foil as a highly charged ion neutralizer. Incident ions like $\mathrm{Th}^{65+}$, were found to reach charge state equilibrium within less than $21 \mathrm{fs}$, loosing approximately $10-15 \%$ of their initial energy in the foil [12]. A beam of $2.75 \mathrm{keV} / \mathrm{u}$ Xe-ions, exiting the foil in charge state equilibrium with $\mathrm{q}_{\mathrm{ave}} \approx 1.5+$, was used as a reference beam for in situ assessment of collisional contributions to observed secondary ion yields. Fig. 4a)-c) show TOF-SIMS secondary ion spectra from a $\mathrm{SiO}_{2}\left(50 \mathrm{~nm}\right.$ on Si) target at impact of $\mathrm{Xe}^{q-q e q}$, $\mathrm{Au}^{69+}$ and $\mathrm{Th}^{70+}$ at $2.75,3.5$ and $1.2 \mathrm{keV} / \mathrm{u}$, respectively. The detection efficiency of the TOF-SIMS setup of $\sim 10 \%$ is not included in this and the following graphs. Positive and negative secondary ions count rates from $\mathrm{SiO}_{2}$ films increase with incident ion charge to $\sim 3.7$ secondary ion counts per incident $\mathrm{HCI}$. Including the detection efficiency results in an ion yield of $\sim 37$ secondary ions/HCI. In comparison, total ablation rates for collisional sputtering of $\mathrm{SiO}_{2}$ by singly charged $1.5 \mathrm{keV} / \mathrm{u}$ Xe-ions have been found to be only $\sim 2.1$ molecules/ion [14]. Negative secondary ion spectra show series of clusters, like $\left(\mathrm{SiO}_{2}\right)_{\mathrm{n}} \mathrm{O}^{-}$, currently detected up to $n=20$, while positive secondary ion spectra are dominated by atomic ions. Fig. 5 a) shows charge state dependencies of negative secondary ion production from $\mathrm{SiO}_{2}(150 \mathrm{~nm}$ on $\mathrm{Si})$ and $\mathrm{C}_{x} \mathrm{H}_{\mathrm{y}}-\mathrm{Au}$ targets as recorded in parallel with the 
above shown secondary electron emission data. Yields of $\mathrm{SiO}_{3}{ }^{-}$and $\mathrm{Si}_{2} \mathrm{O}_{5}{ }_{5}^{-}$can be fit with satisfactory agreement to a $q^{4}$-dependency on incident ion charge and are found to increase up to the highest incident charge states. On the contrary, $\mathrm{C}_{2} \mathrm{H}_{\mathrm{y}}{ }^{-}(\mathrm{y} \leq 3)$ from the hydro-carbonated Au target saturate for $\mathrm{q}>64+$, indicating complete removal of hydrocarbons from the $\mathrm{HCI}$-surface interaction region. The charge state dependency of total positive and negative secondary ion production from $\mathrm{SiO}_{2}(50 \mathrm{~nm}$ on $\mathrm{Si})$ is shown in Fig. 5 b). Incident ions were $\mathrm{Xe}^{\mathrm{q}=q 99}, \mathrm{O}^{7+}, \mathrm{Xe}^{15,20,24,27,30,35,40,44,52+}$ and $\mathrm{Au}^{60,69+}$ at kinetic energies of $3.5 \mathrm{keV} \times \mathrm{q}$ (positive) and $10 \mathrm{keV} \times \mathrm{q}$ (negative). The semi-logarithmic scale was chosen to demonstrate the charge based increase in secondary ion production over three orders of magnitude from the collisional limit $\left(\mathrm{Xe}^{\mathrm{q}=q 99}\right)$ to $\mathrm{Au}^{69+}$.

Electronic energy loss effects on damage production, sputtering and desorption [15] have been studied extensively using beams of fast heavy ions $\left(\mathrm{E}_{\mathrm{kin}}>1 \mathrm{MeV} / \mathrm{u}\right)$. In conductors, electronic excitation of target atoms can be dissipated more efficiently than in insulators. Consequently, stopping power thresholds for electronic damage production are found to be higher for metals $[9,16,17]$ than for insulators [18]. In the interaction of slow HCI with solids, electronic excitation of target material is driven by the dissipation of tens to hundreds of $\mathrm{keV}$ of ion potential energy into a surface near target volume. In analogy to nuclear track formation in the ion explosion spike model [19], Parilis et al. predict the onset of electronic sputtering in a given material when the Coulomb stress between ionized target atoms in a charge depleted $\mathrm{HCI}$ impact region exceeds their remaining binding energy [8].

The following signatures of Coulomb explosions are consistent with the presented data. A threshold for onset of electronic sputtering is indicated by a cross-over of positive 
and negative secondary ion production rates, the ratio of which is found to be constant for $\mathrm{q} \geq 30+$. Secondary ion production rates from clean $\mathrm{Au}$ at impact of slow $\mathrm{HCI}$ are in agreement with yields expected from collisional sputtering, we measured $\sim 10^{-3} \mathrm{Au}^{+}$-counts per $\mathrm{Xe}^{44+}$-ion. Positive secondary ions are emitted from a region of high ionization density dominantly as atomic ions. The rapid expansion of highly ionized target material leads to the creation of a shock-wave [20]. High yields of intact cluster ions are emitted from the fringe of the interaction region by the correlated movement of the shock-wave front.

Cluster ion formation reflects the chemical properties of the target material, negatives are preferred for oxides, positive clusters have been observed for $\mathrm{HCI}$ impact e. g. on $\mathrm{CaF}_{2}$ [21].

The Coulomb-explosion-shock-wave model predicts a power law dependency of cluster yields on cluster size $n, Y \sim n^{2}$, with $a \approx-2$, whereas a model of statistical cluster formation [22] predicts cluster yields to decrease exponentially with cluster size $\left(Y \sim e^{-n}\right)$. $\left(\mathrm{SiO}_{2}\right)_{\mathrm{n}} \mathrm{O}^{-}$clusters yields, previously measured up to $\mathrm{n}=10$, were found to follow a power law dependency with $a \approx-2.6[11,23]$, in agreement with data presented here. In comparison, power law exponents for -neutral- cluster emission in collisional sputtering are typically a $<-5$ [24]. Earlier theoretical considerations on combinatorial cluster formation from $\mathrm{SiO}_{2}$ at $\mathrm{HCI}$ impact [25], based on data from initial studies with $\mathrm{n}<6$, can be revised and expanded to include these new findings.

Secondary ion yield increases with ion charge are thought to be a convolution of an increase in total ablation rate and higher ionization probabilities, resulting in a cubic dependency of ion yields with incident ion charge [8]. A weaker q-dependency of positive secondary ion yields has been attributed to less efficient conversion of $\mathrm{HCI}$ potential 
energy into target excitation due to emission of energetic Auger electrons. It is unclear at this point if cluster ion formation probabilities are charge dependent or not. In analogy to electronic desorption of intact bio-molecules, applicability of shock-wave [20] or pressurepulse [26] models would indicate that cluster ionization probabilities are largely independent of $\mathrm{HCI}$ charge and amount to $\sim 10^{-4}$ cluster-ions per amount of ablated material [27]. Measurements of total ablation rates are being performed.

The Coulomb explosion model does not include any discussion of desorption induced by electronic transitions. The results from hydro-carbonated Au targets show that desorption of surface adsorbates by $\mathrm{HCI}$ impact is very efficient, with desorption yields in

the order of $\sim 17 \mathrm{C}_{2} \mathrm{H}_{\mathrm{y}}^{-}$molecules per $\mathrm{Au}^{66+}$. A recently presented generalized MenzelGomer-Redhead model of desorption induced by multiple electronic excitations [28], could be very useful to extend the understanding of desorption phenomena in the presence of high electronic excitation densities as they can be generated at surfaces e. g. by short pulse lasers and slow $\mathrm{HCI}[12]$.

\section{Conclusion}

Substantially lower secondary electron emission rates from $\mathrm{SiO}_{2}$ films as compare to Au surfaces challenges the current understanding of $\mathrm{HCl}$ de-excitation at/in insulators. This challenge will be addressed in future systematic studies of materials parameters in $\mathrm{HCI}$ induced electron emission.

Secondary ion production rates in $\mathrm{HCI}$ interactions with $\mathrm{C}_{x} \mathrm{H}_{y}-\mathrm{Au}$ and $\mathrm{SiO}_{2}$-films show substantial increases over corresponding rates in collisional sputtering. Characteristic signatures of electronic sputtering by Coulomb explosions are observed at 
$\mathrm{HCI}$ impact on $\mathrm{SiO}_{2}$ films. Measurements of high yields of desorbed surface adsorbates from $\mathrm{C}_{x} \mathrm{H}_{y}-\mathrm{Au}$ targets demonstrate the importance of electronic excitation processes in HCI solid interactions.

\section{Acknowledgments}

The authors thankfully acknowledge the excellent technical support at the Lawrence Livermore National Laboratory EBIT facility provided by D. Nelson, K. Visbeck and P. DAntonio. One of the authors (TS) wants to express his gratefulness for continuous support from Professors K. Bethge and H. Schmidt-Böcking.

This work was performed under the auspices of the U. S. Department of Energy by Lawrence Livermore National Laboratory under contract No. W-7405-ENG-48.

\section{References}

[1] K. Shima, N. Kuno, M. Yamanouchi, Phys. Rev. A 40, (1989) 3557

[2] D. H. Schneider and M. A. Briere, Physica Scripta, 53 (1996) 228, and references therein

[3] J. Burgdörfer, P. Lerner and F. M. Meyer, Phys. Rev. A 44 (1991) 5674; J. Burgdörfer and F. M. Meyer, Phys. Rev. A 47 (1993) R20; J. Burgdörfer, C. Reinhold, L. Hägg, F. Meyer, Aust. J. Phys. 49 (1996) 527

[4] HP. Winter, M. Vana, C. Lemmell, F. Aumayr, Nucl. Instr. and Meth. B 115 (1996) 224, F. Aumayr, H. Kurz, K. Töglhofer, HP. Winter, Nucl. Instr. and Meth. B 78 (1993) 99 
[5] J. W. McDonald, D. Schneider, M. W. Clark and D. DeWitt, Phys. Rev. Lett. 68, $2297(1992)$

[6] F. Aumayr, H. Kurz, D. Schneider, M. A. Briere, J. W. McDonald, C. E. Cunningham, and HP. Winter, Phys. Rev. Lett. 71, 1943 (1993), H. Kurz, F. Aumayr, HP. Winter, D. Schneider, M. A. Briere, J. W. McDonald, Phys. Rev. A 49 (1994) 4693

[7] J. Limburg, S. Schippers, R. Hoeckstra, R. Morgenstern, H. Kurz, F. Aumayr, HP. Winter, Phys. Rev. Lett. 75 (1995) 217

[8] I. S. Bitenskii, M. N. Murakhmetov, and E. S. Parilis, Sov. Phys. Tech. Phys. 24 (5) 1979, 618; E. S. Parilis, Z. Phys. D - Atoms, Molecules and Clusters 21 (1991) 127; I. S. Bitensky, E. S. Parilis, S. Della-Negra and Y. Le Beyec, Nucl. Instr. and Meth. B 72 (1992) 380

[9] S. T. de Zwart, T. Fried, D. O. Boerma, R. Hoekstra, A. G. Drentje, A. L. Boers, Surface Science 177 (1986) L939

[10] S. Della-Negra, J. Depauw, H. Joret, V. Le Beyec, E. A. Schweikert, Phys. Rev. Lett: 60 (1988) 948

[11] M. A. Briere, T. Schenkel, D. Schneider, in Proceedings of SIMS X, Münster, Oct. 1995; T. Schenkel, M. A. Briere, A. E. Schach von Wittenau, D. Schneider, in Proceedings 43rd ASMS Conf. on Mass Spectrometry and Allied Topics, Atlanta, May 1995

[12] T. Schenkel, M. A. Briere, A. V. Barnes, A. Hamza, H. Schmidt-Böcking, K. Bethge, D. Schneider, submitted for publication

[13] R. A. Baragiola, in J. W. Rabalais (ed.), Low Energy Ion-Surface Interactions (Wiley, Chichester, 1994), P. 190 
[14] H. Jacobson, G. Holmen, Nucl. Instr. and Meth. B 82 (1993) 291; ibid., Phys. Rev. B 49 (1994) 1789; ibid., J. Appl. Phys. 74 (1993) 6397; ibid., J. Appl. Phys. 75 (1994) 8109

[15] K. Wien, Rad. Effects and Defects in Solids 109 (1989) 137, and references therein

[16] A. Audouard, et al., Phys. Rev. Lett. 65 (1990) 875

[17] H. Dammak, A. Dunlop, D. Lesueur, A. Brunelle, S. Della-Negra, Y. Le Beyec, Phys. Rev. Lett. 74 (1995) 1135

[18] F. Thibudau, J. Cousty, E. Balanzat, S. Bouffard, Phys. Rev. Lett. 67 (1991) 1582

[19] L. Fleischer, P. B. Price and R. M. Walker, Nuclear Tracks in Solids, (University of California Press, Berkeley, 1975)

[20] I. S. Bitensky, E. S. Parilis, Nucl. Instr. and Meth. B 21 (1987) 26; E. S. Parilis, private communication

[21] to be published

[22] W. Gerhard, Z. Physik B 22 (1975) 31

[23] M. A. Briere, T. Schenkel, D. H. Schneider, EBIT-Annular Report 1994, P. 38, Lawrence Livermore National Laboratory, UCRL-ID-121572

[24] A. Wucher, M. Wahl, Nucl. Instr. and Meth. B 115 (1996) 581 and references therein

[25] G. Schiwietz, M. Briere, D. Schneider, J. McDonald, C. Cunningham, Nucl. Instr. and Meth. B 100 (1995) 47

[26] R. E. Johnson, B. U. R. Sundqvist, A. Hedin, D. Fenyö, Phys. Rev. B 40 (1989) 49; D. Fenyö, R. E. Johnson, Phys. Rev. B 46 (1992) 46

[27] M. Salehpour, P. Hakansson, B. Sundqvist, S. Widdiyasekra, Nucl. Instr. and Meth. B 13 (1986) 278 
[28] J. A. Misewich, T. F. Heinz and D. M. Newns, Phys. Rev. Lett. 68 (1992) 3737 


\section{Figure Captions:}

Fig. 1: Pulse height distributions of integrated electron emission signals as detected with an annular micro channel plate detector.

Fig. 2: Relative and absolute electron yields from thin $\mathrm{SiO}_{2}$ films $(150 \mathrm{~nm}$ on $\mathrm{Si})$ and $\mathrm{C}_{x} \mathrm{H}_{\mathrm{y}}-\mathrm{Au}$ surfaces as a function of incident ion charge state $\mathrm{q}$.

Fig. 3: Velocity dependency of secondary electron emission from $\mathrm{C}_{\mathbf{x}} \mathrm{H}_{\mathbf{y}}-\mathrm{Au}$ and thin $\mathrm{SiO}_{2}$ films $(150 \mathrm{~nm}$ on $\mathrm{Si})$ and of positive secondary ion emission from $\mathrm{SiO}_{2}$ films at impact of $\mathrm{Xe}^{44+}$.

Fig. 4: Negative secondary ion production from $\mathrm{SiO}_{2}\left(50 \mathrm{~nm}\right.$ on Si) at impact of a) $\mathrm{Xe}^{\mathrm{q}=q e q}$ and b) $\mathrm{Au}^{69+}$. c) Production of positive secondary ions at impact of $\mathrm{Th}^{70+}$.

Fig. 5: a) Charge state dependent production of $\mathrm{SiO}_{3}{ }^{-}$and $\mathrm{Si}_{2} \mathrm{O}_{5}{ }^{-}$from $\mathrm{SiO}_{2}(150 \mathrm{~nm}$ on $\mathrm{Si})$ and $\mathrm{C}_{2} \mathrm{H}_{\mathrm{y}}-$ from $\mathrm{C}_{\mathrm{x}} \mathrm{H}_{\mathrm{y}}-\mathrm{Au}$ targets as recorded in parallel with electron emission data from Fig. 1 and 2. b) Integrated positive $\left(\mathrm{Y}^{+}\right)$and negative ( $\left.\mathrm{Y}^{-}\right)$secondary ion counts/ $\mathrm{HCI}$ from $\mathrm{SiO}_{2}(50 \mathrm{~nm}$ on $\mathrm{Si})$ as a function of incident ion charge q. The detection efficiency of the TOF-SIMS setup $(-10 \%)$ is not included. 


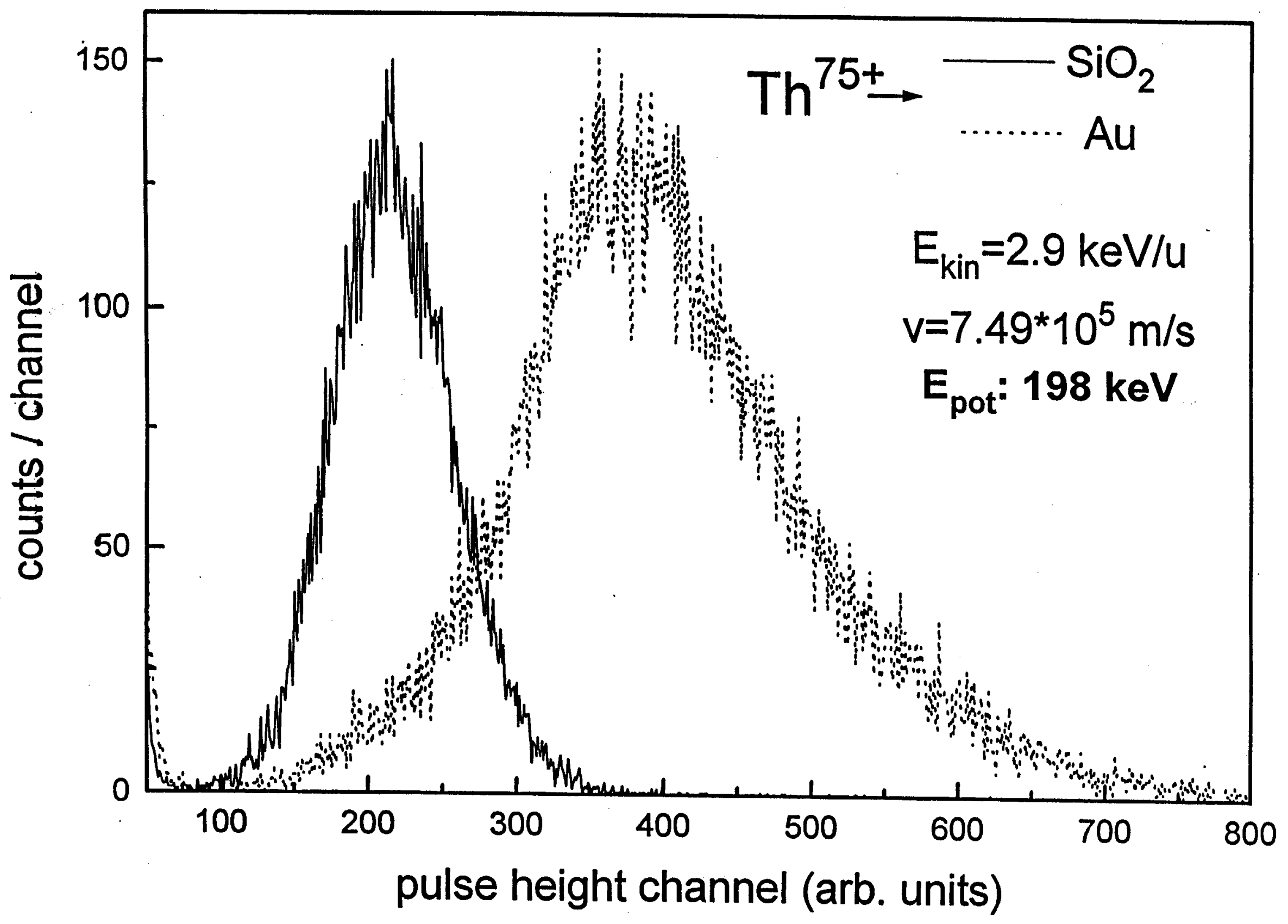

Fig. 1 


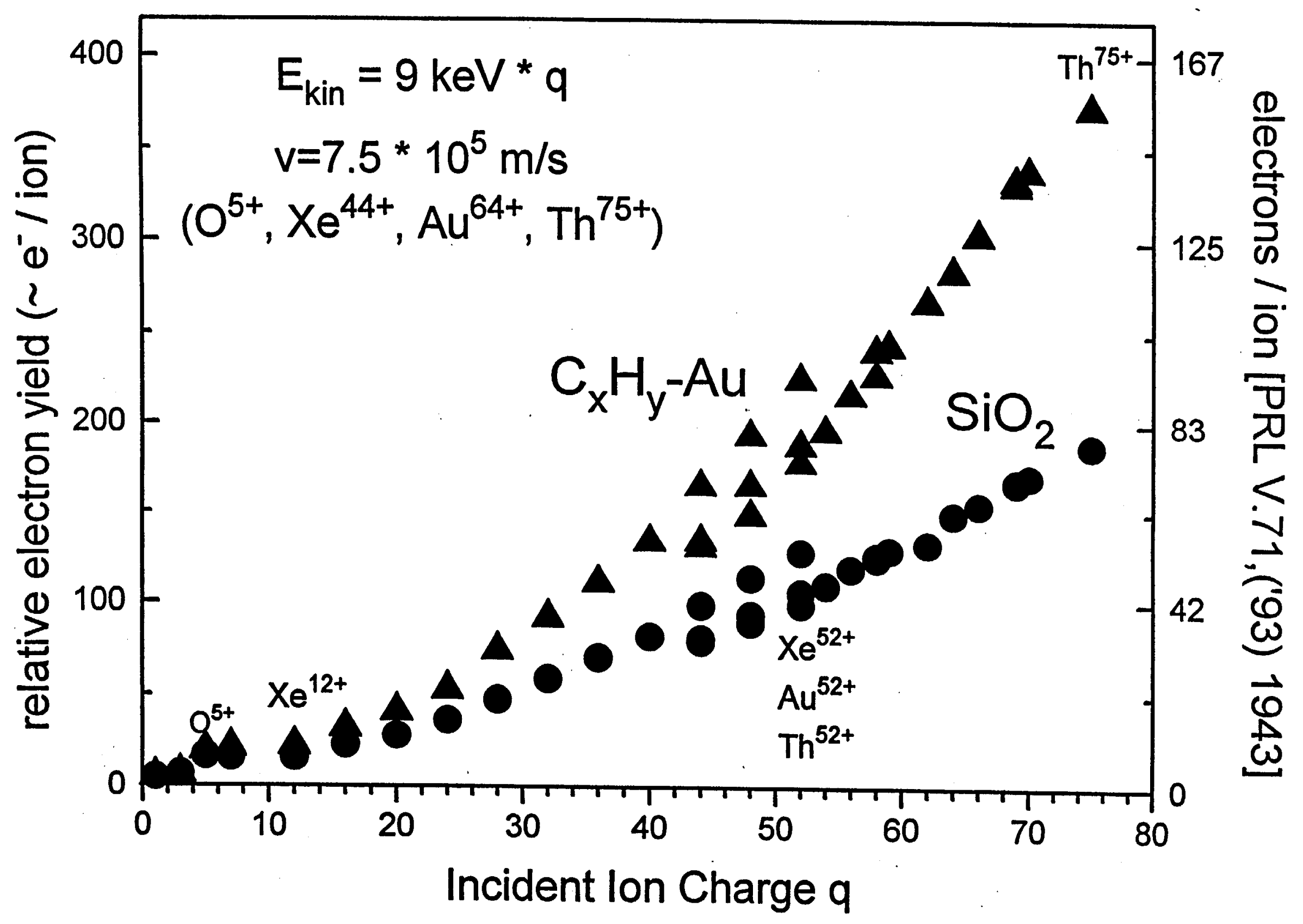

Fig. 2 


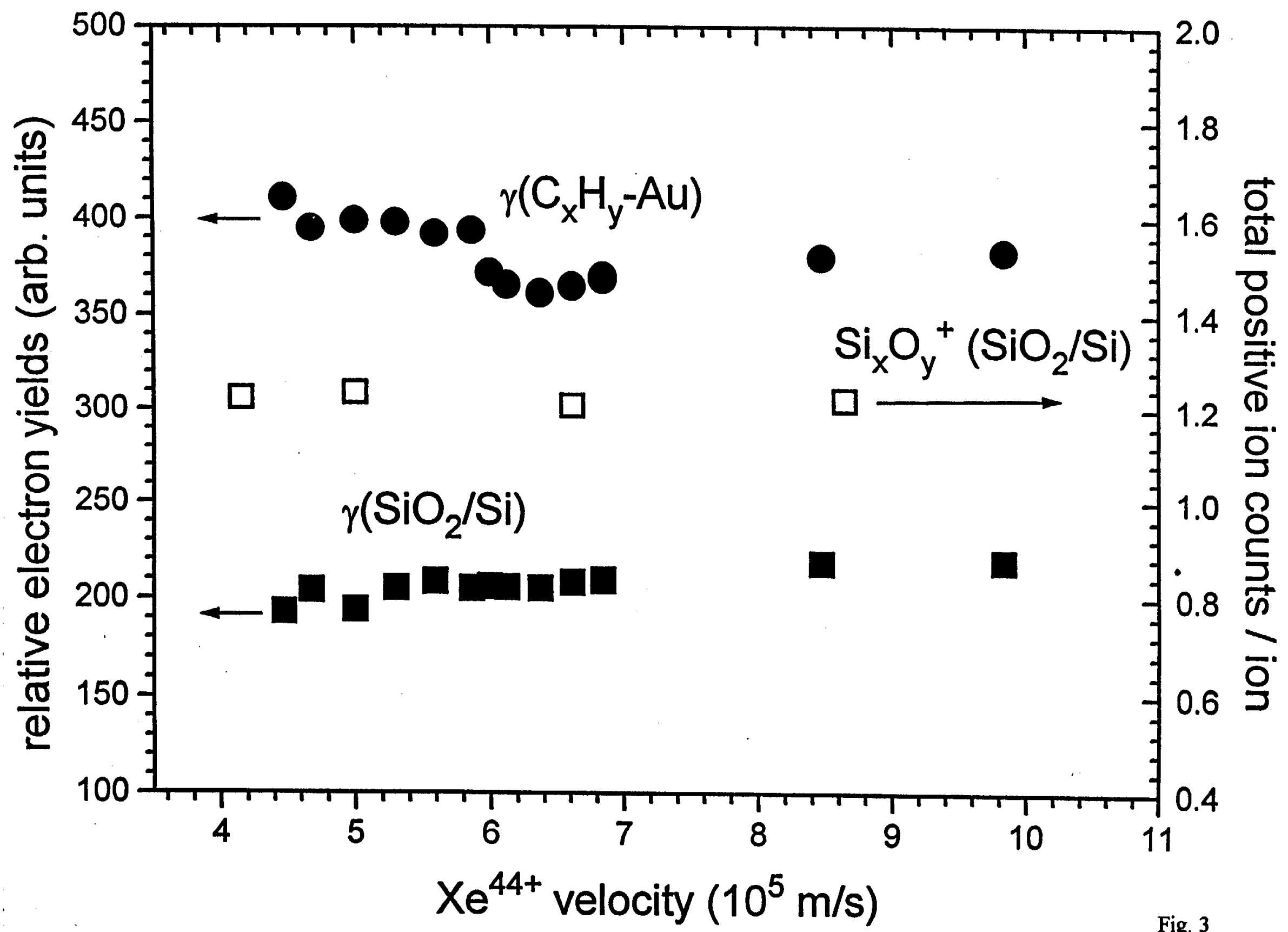

Fig. 3 


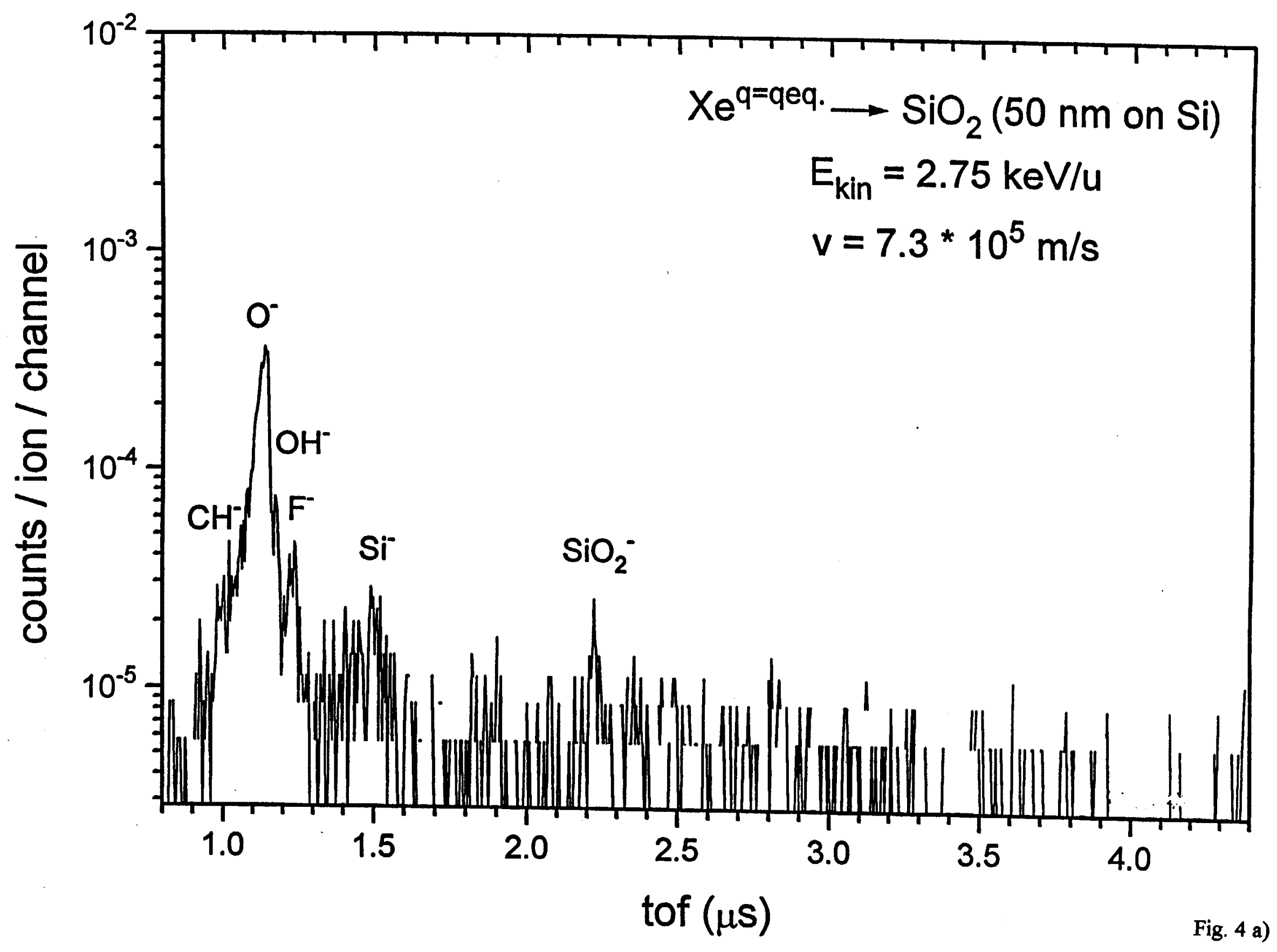




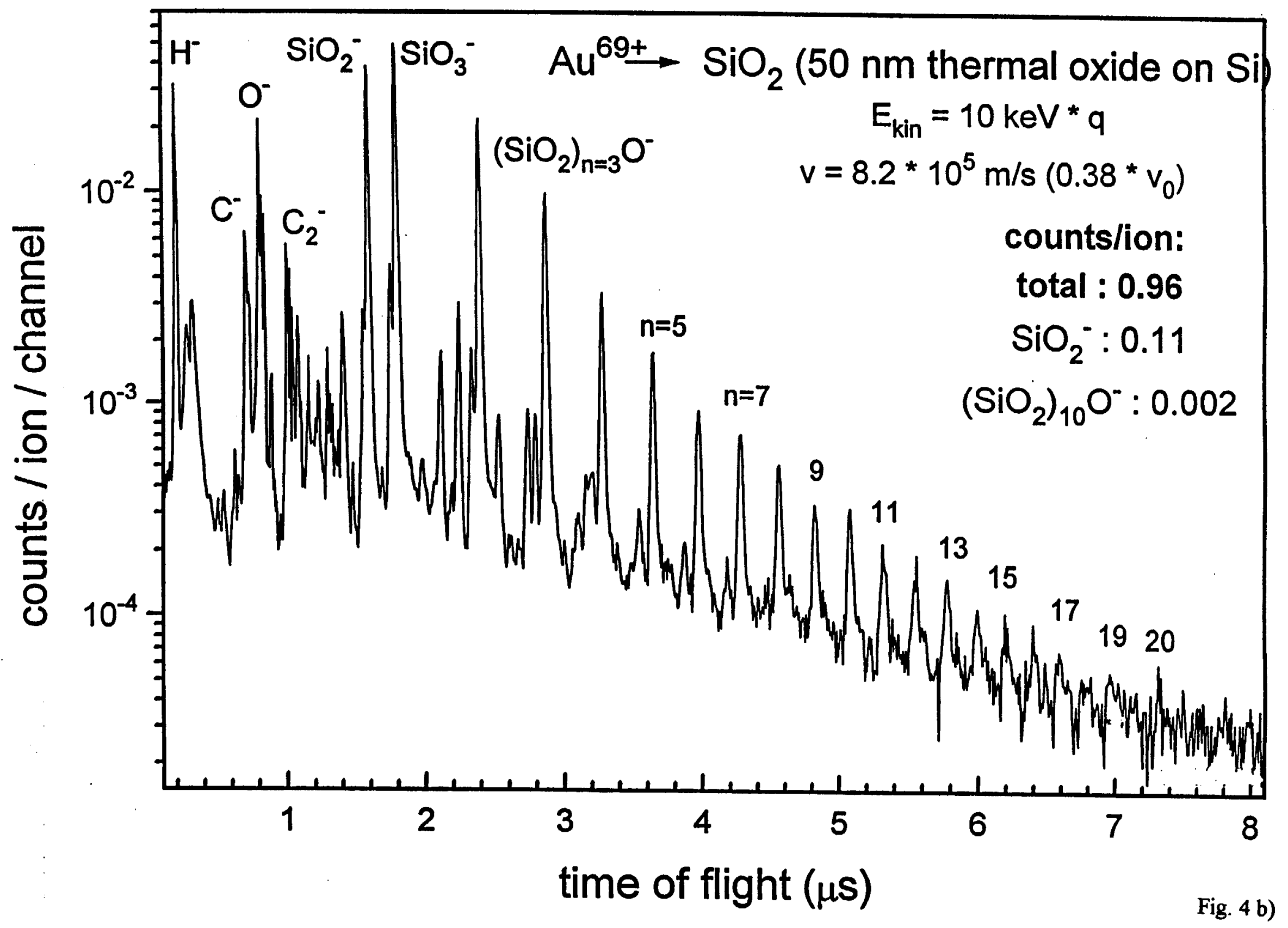




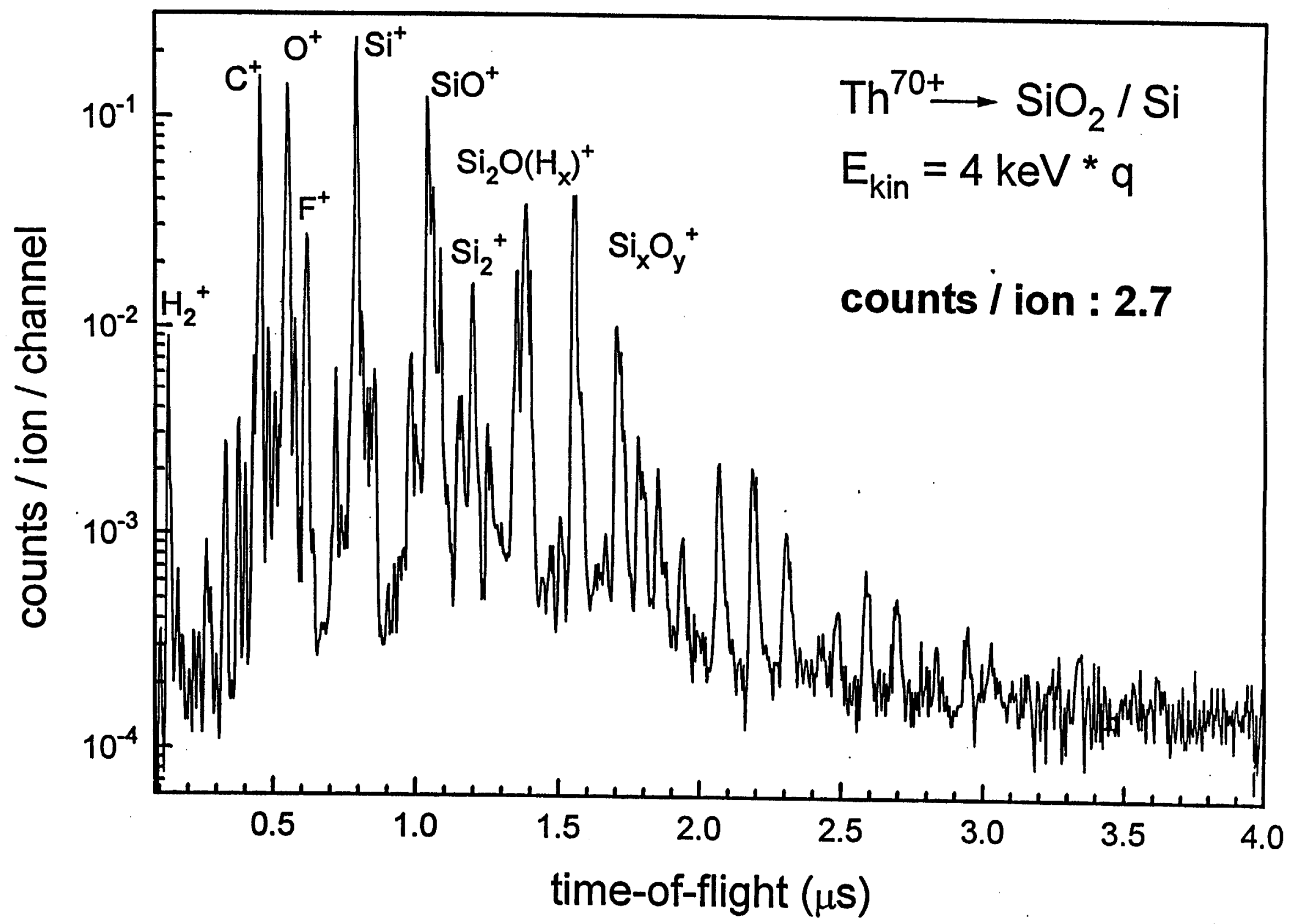

Fig. 4 c) 


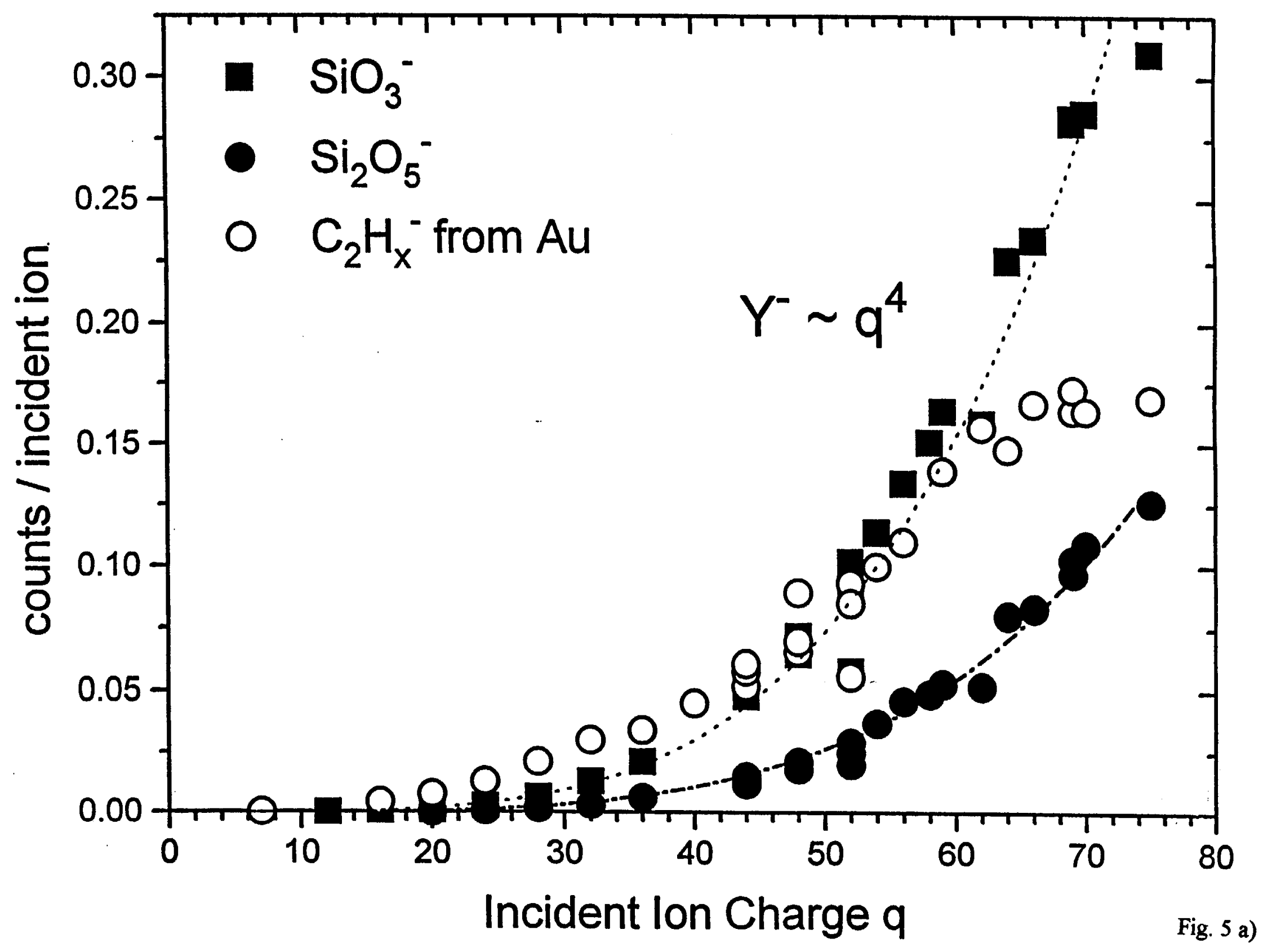




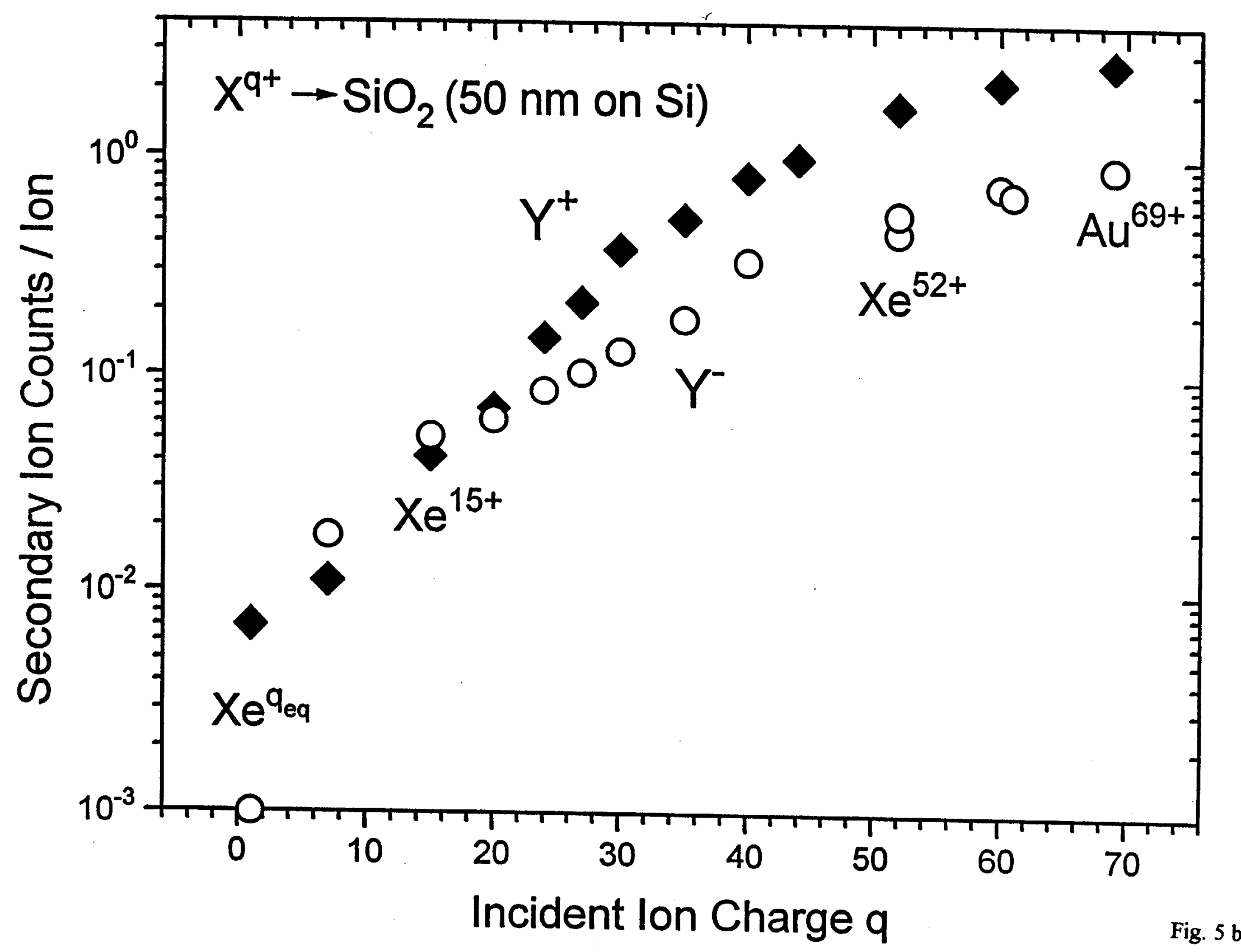




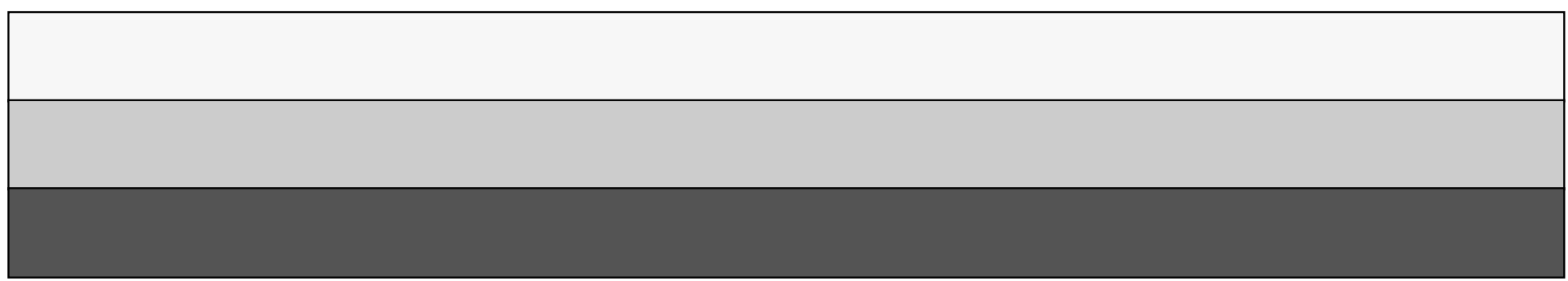

